\title{
Ground searches for graves and buried targets related to homicide, terrorism and organised crime
}

\author{
${ }^{1}$ Arup, $6^{\text {th }}$ Floor, 3 Piccadilly Place, Manchester, M1 3BN, UK; Chair, International Union of Geological Sciences, Initiative on Forensic \\ Geology (IUGS-IFG); *Corresponding author, E-mail: Laurance.Donnelly@arup.com; geologist@hotmail.co.uk \\ ${ }^{2}$ Australian Federal Police; Geoforensic Law Enforcement Adviser, International Union of Geological Sciences, Initiative on Forensic Geology \\ (IUGS-IFG) \\ ${ }^{3}$ University of Canberra, Canberra, ACT 2601, Australia
}

(Received: October 28, 2016; Revised accepted: March 5, 2017)

http://dx.doi.org/10.18814/epiiugs/2017/v40i2/017012

Geologists explore the ground to locate mineral resources, investigate and characterise the properties and behaviour the soils and rocks as part of a geotechnical ground investigation and for geohazard assessments. Similarly, the police may search the ground to locate homicide graves, weapons, firearms, drugs or items of value that have been buried beneath the ground surface as part of a criminal or terrorist act. Historically, the methods and techniques used by geologists and law enforcement evolved separately. Conventionally, geologists and law enforcement officers worked in isolation to explore and investigate or search the ground. Over the past decade the authors, with different and complimentary capabilities, began working in collaboration during the search for a grave. This provided the opportunity and incentive for geological and law enforcement investigative strategies to be brought together. This has enabled the development of a high assurance ground search strategy. This paper provides an overview of ground searches how these have advanced and developed.

\section{Historical Overview}

Police ground search conventionally deployed line searching (also called 'finger-tip' searching). This comprises a line of officers and/or volunteers that would systematically walk across a pre-determined area of ground in an attempt to identify any surface evidence for digging and burial. The interpretation of aerial photographs, trial and error excavations, limited use of geophysics and the deployment of detector dogs were also used as part of police searches. These searches were variably successful owing to the absence of any geomorphological or topographic features associated with the digging of a grave or the failure to recognise the often subtle ground disturbances associated with a grave.

In 1984, the Provisional Irish Republican Army (IRA), a terrorist group operating mainly in Northern Ireland, planted a time delayed bomb in a hotel room in Brighton, UK, in an attempt to assassinate
Prime Minister at this time (Margaret Thatcher) and her cabinet. The prime minister survived although there were a number of fatalities. In the aftermath, the British Police embarked on training with the UK military who were experienced in counter terrorism searches.

In 1994, a geological approach was developed to search for a suspected grave. For the first time this enabled geological and law enforcement search methods to be brought together and blended. What emerged was a new, high assurance search strategy so that the ground may be searched in a cost-effective, pragmatic and timely manner to locate or prove the absence of a target, consistent with the limitations of the assets and intelligence available (Donnelly and Harrison, 2010).

\section{Ground Searches}

A search has been defined as, "The application and management of systematic procedures and appropriate detection equipment to locate specific targets" (Harrison et al., 2006). Search has also been defined as, "The capability to locate specified targets using intelligence assessments, systematic procedures and appropriate detection systems" (ACPO, 2012).

Ground search is an important aspect of policing and law enforcement. Searches must not be random but carefully planned, coordinated, managed and based on reliable and accurate intelligence. The search strategy must consider for example: the search type, outer boundary of the search areas, likelihood that the target can be located, properties and condition of the target, objectives and extent of the search, required resources, choice of search assets, press management, family members (if the search is for a suspected homicide grave), cost, time frames, relevance, geology and ground conditions.

It is recommended that ground searches are carried out from the macro to the micro scale and from the non-invasive to the invasive. This approach permits the effective management of the crime scene to avoid the possibility of cross contamination. Once the desired target has been located the geologist will usually interface with a forensic specialist for formal identification, recovery and recording.

Ground searches may take place in a range of settings, from the confines of a small garden defined by boundary fences, walls or hedges to 
vast expanse of a land such as: a cost lines, deserts or mountainous environment. Each geographical settings is unique and requires a specific search approach in terms of the strategy deployed. For example, the evidential search of small garden behind a house in Eastern England house took a small search team two days for this to be completed. When a search was being considered for a missing person in Australia, the outer boundaries of the search area extended the equivalent distance from London to Rome, when plotted on a map of Europe. Clearly, a different search strategy was required in each of these two extreme cases. A ground search can also be influenced by the time, costs, available resources and time or media pressures. Some ground searches may be completed following just a couple of hours searching. Alternatively, they could take days to weeks or in some situations many years. Some searches never become resolved even though the intelligence strongly provides a search area. This is the nature of search and the uncertainties that searches may bring. Whatever the outcome of a search, a pre-determined exit strategy is required, and where relevant appropriate press and media management.

\section{Search Types}

In addition to ground searches police also search vehicles (cars, vans, trucks, bikes), vessels (boast and ships) water bodies (streams rivers, estuaries, canals, seas, ocean and reservoirs) (Ruffell 2006). An offensive or detective search is carried out when evidence is required after a crime has occurred. An objective of this type of search would be to find a murder victim's grave or other buried or concealed evidence or to deprive criminals of their resources and opportunities to commit crimes. Whereas, a protective or defensive search is proactive and is deployed to confirm the absence of a specified item, object or person within an area or specified location. Essentially, this type of search allows the freedom of movement and access of people and the general public in a safe secure environment.

There are different categories of search. The police may search a person who has been arrested or detained or a persons' possessions. Searches may also be undertaken to find a person or people when they go missing, whereby this could be voluntarily (e.g., to commit suicide), involuntarily (e.g., they have been kidnapped) or they are lost (e.g., a walker or climber) and they are active in their own self-discovery (in other words they want to be found). This may lead to the deployment of a "Search and Rescue" type of search. In this search type a missing person's last known place is important. A premise is then made that the person can walk a given distance in the time elapsed since the last siting or known recorded location and a search area radius can be identified. If the search area is large, this may be divided into sectors and appropriate resources assigned to each search sub-sector.

All ground searches must be intelligence informed and based on a credible hypothesis, which is usually led by the police investigation team. Similarly, geological search strategies should also be based on an understanding of the ground conditions, target properties and expected detectability. This will ensure the geological components of the search are justified, measureable, cost effective and proportionate in context of the buried item being sought (Harrison and Donnelly, 2007, 2008, 2009).

Scenario Based Searches requires an evaluation of the offender's and victims movements and an analysis of the likely dynamics of a crime scene or search area. This search type considers all available and reliable intelligence, behaviour profiles, environmental profiles and enables hypothesis generation. This may help to better understand a missing person's disappearance. Often these types of searches require the forensic geologist to work with other specialists such as behavioural profilers, clinical psychologists, and law enforcement intelligence analysts. Some police forces have databases on missing persons that could assist in helping to identify search areas. Scenario Based Searches reduces the likelihood that a search will be conducted based on subjective opinions of an individual.

A Feature Focused Search method is based on the premise that physical, geological or geomorphological features of the landscape aid an offender to locate a grave or relocate a burial (such as weapons or drugs). If the offender's modus operandi (MO) can be decoded, this can assist in reducing the search area. Feature Focused searches (sometimes referred to as "Reference Point Searching" and formerly known as "Winthropping"), developed as a military technique to assist in identifying the location of buried objects and terrorist hides. This relies on the ability to identify the relevance of geological, geomorphological or physical features of the landscape to locate and relocate hides. This method may enable and offender and their accomplice retrieve buried items by the recognition of distinct "primary", "secondary" and "tertiary" Primary Reference Point Markers.

\section{Phase 1: Pre Search}

\section{Search Phases}

The authors advocate the division of a ground search into three distinct, defined, proportionate, achievable and measurable phases: known as the pre-search, search and post search (Donnelly and Harrison, 2010, 2013, 2015; Donnelly, 2013a). A forensic geologist must have the ability to effectively communicate with the law enforcement

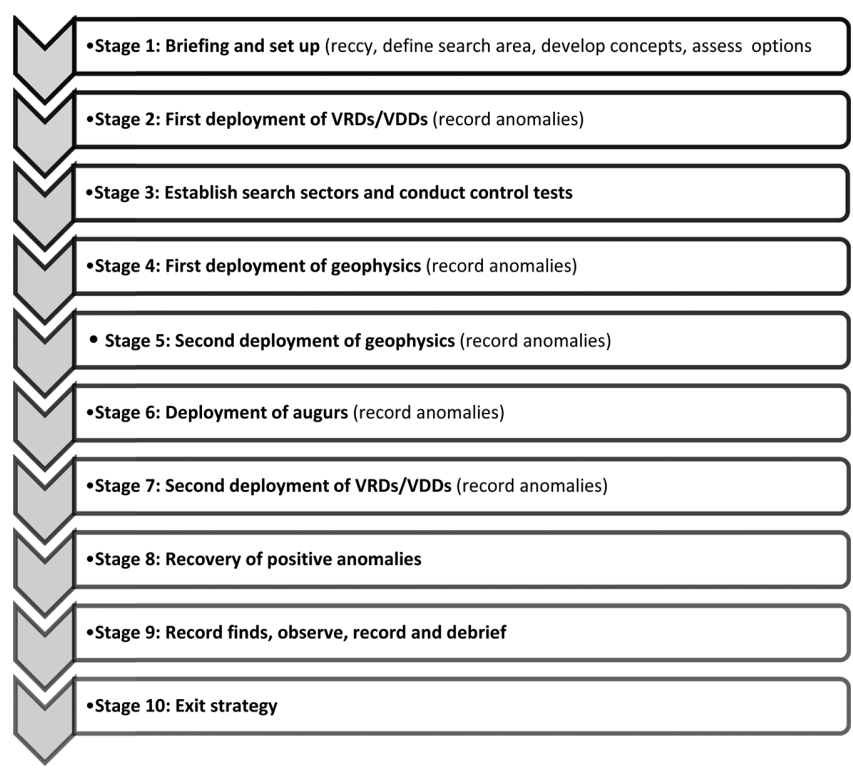

Figure 1. Idealised search methodology (After Donnelly and Harrison, 2015). 
officer when invited to assist with a ground search. The geologist must carefully consider of the levels of geological knowledge of the investigating officer and use geological terminology appropriately explaining the usage of any scientific terms where appropriate (Donnelly, 2008a) (Fig. 1).

\section{Initial Briefing}

During the initial briefing with the police the type of search should be identified. At this stage, the forensic geologist should be provided with or request the case background and intelligence. This may include interview notes, statements, surveillance material, exhibits and photographs of the crime scene or search area. For example, following the terrorist attack on the World Trade Centre in New York a video message form Osama Bin Laden showed a sequence of sedimentary strata in the background. The geological analysis of this strata by a USA geologist identified an area of $93 \mathrm{~km}^{2}$ in south-eastern Afghanistan. In the 1960s and 1980s, the recognition of geological features in northern England on photographs in the possession of offenders led to the discovery graves. Any exhibits or items the police may have seized should be inspected. These may include clothes, a vehicle, tools (such as a spade) as these could contain traces of soil, superficial deposits, rock fragments, minerals or anthropogenic materials transferred from a burial site or crime scene. The sampling and analysis of these materials could indicate the geographical provenance of the collected samples (Pirrie et al., 2009).

\section{Desk Study}

A desk study allows all materially relevant data and information, and case intelligence, to be collated and analysed. As a minimum this should include the analysis of geological maps, memoirs, reports and publications that are typically available for any federal or national geological survey. If relevant, other data may include mine abandonment plans, cave maps, past edition topographic maps and information from local interests groups. The acquisition of high resolution air photos, Google Earth imagery, LiDAR, hyperspectral or thermal imagery or satellite imagery may reveal subtle ground disturbances potentially associated with a burial and enable the geology to be evaluated. Air reconnaissance observations from a police/military/search and rescue helicopter is of particular value for open areas searches so that the context and outer limits of the search area can be determined and topographic ground disturbances observed. In 2003, the dismembered remains of a homicide grave were found in the UK following the geomorphological analysis of air photos. Remote sensing surveys also assisted to locate graves in Colombia, during 2002-2004, associated with drug cartels.

\section{Reconnaissance}

Reconnaissance walk-over surveys provide the opportunity for a Conceptual Geological Model (CGM) to be produced, the ground diggability to be evaluated and the search area limits to be defined. Sometime a "quick win" is possible, where evidence for a burial is found during the initial visit. This may be the exposure of human remains by weathering and erosion or the recognition of topographic features associated with digging a grave or hide. Typically, this may include: (a) settlement of the backfilled material above the target, (b) colour changes caused by lower soil layers being placed on the ground surface, (c) the occurrence of excessive material caused by the bulking of the displaced soil and the additional volume taken up by the target, (d) enhanced or reduced vegetation, (e) changes in vegetation and (d) animal scavenging of increased insect activity due to decomposition.

\section{Profiling}

Behavioral profiling may provide information on an offenders possible movements and the dynamic of a crime scene that could assist the forensic geologist in identifying search sites. Environmental profiling could also be of value, for example a forensic palynologist may assist in determining anomalous vegetation growth above a burial. In addition, the analysis of pollen could provide information on the provenance of a victim or item suspected by the police to be used during the crime (Wiltshire, 2009, 2015).

\section{Detectability}

The detectability of a buried target considers the likelihood of a buried target being found and the search assets most suitable to locate the target. Detectability can be considered in terms of organic targets such as human remains or non-organic targets such as firearms or drugs. For instance, searching for buried human remains will require a different approach than searching for buried firearms. The latter generally contain a high metal content that are detectable many years after burial. By comparison, the preservation of decomposition of human remains will be dependent on several factors such as: (a) the time elapsed since burial, (b) cause of death, (c) whether the body was wrapped in cloth, plastic or other material, (d) temperature, (e) scavenging, (f) post burial weathering and erosion and (g) anthropogenic landscape modifications. Inorganic items will decompose at different rates, from weeks to hundreds of years, depending on what they are composed of, such as cotton, silk, leather, metal, alloys, glass or plastic. Generally, granular soils tend to promote decomposition, whereas clay rich and organic soils may preserve human tissue over prolonged periods of time. A judgement on whether a target can be realistically, practicably, cost-effectively and timely located with the resources available, should be determined by the forensic geologist and law enforcement officer in the early stages of a search.

\section{Diggability}

Diggability considers the relative ease by which the soils can be dug and then reinstated into a grave. This depends on the engineering properties and geotechnical behaviour of the soils includes the soil type, strength, depth, bulking characteristics, presence of boulders and groundwater. The method of excavation is also relevant depending on whether the grave or hide has been dug using hand held tools (such as a spade, pick or mattock) or mechanised plant machinery. Ground that is diggable with difficulty using a spade may become diggable with ease if a mechanical digger may have been used by the offender. Red-Amber-Green (RAG) prioritisation maps may be used to denote diggability (Donnelly 2013b). These enable police resources to 
become allocated to areas of higher priority and most likely to contain the buried target. On some police and military RAG maps 'red' indicates the highest priority, whereas on geological RAG maps it is 'green'. RAG maps must always have a legend to denote the highest and lowest priority areas (Donnelly and Harrison, 2013).

\section{Conceptual Geological Model}

The production of a Conceptual Geological Model (CGM) is recommended for all ground searches. A CGM provides a preliminary evaluation of the geology and expected ground conditions. This can be based on the interpretation of geological maps, memoirs, technical and scientific reports and papers, which are typically available from national geological surveys or on-line. As a minimum the CGM should include information on: (a) geology (e.g., stratigraphy, lithology (principal soil and rock types), (b) structural geology, (c) depth to bedrock, (d) nature of bedrock interface, (e) weathering and erosion, (f) engineering properties of the soils and rocks (e.g., soil density, moisture, strength, thickness), (g) geophysical properties (e.g., conductivity, resistivity, magnetic, electromagnetic, gravity), (h) hydrogeology (e.g., groundwater flows and direction), (i) geomorphological processes before, during and since burial took place, (j) anthropogenic features (e.g., building and wall foundations, utilities, areas of tipping or digging), (k) diggability and (l) detectability. The CGM should be verified by a site reconnaissance 'walk-over' and upgraded as more geological information and case intelligence becomes available. The benefits of

Subtle change in morphology of ground (settlement/subsidence)

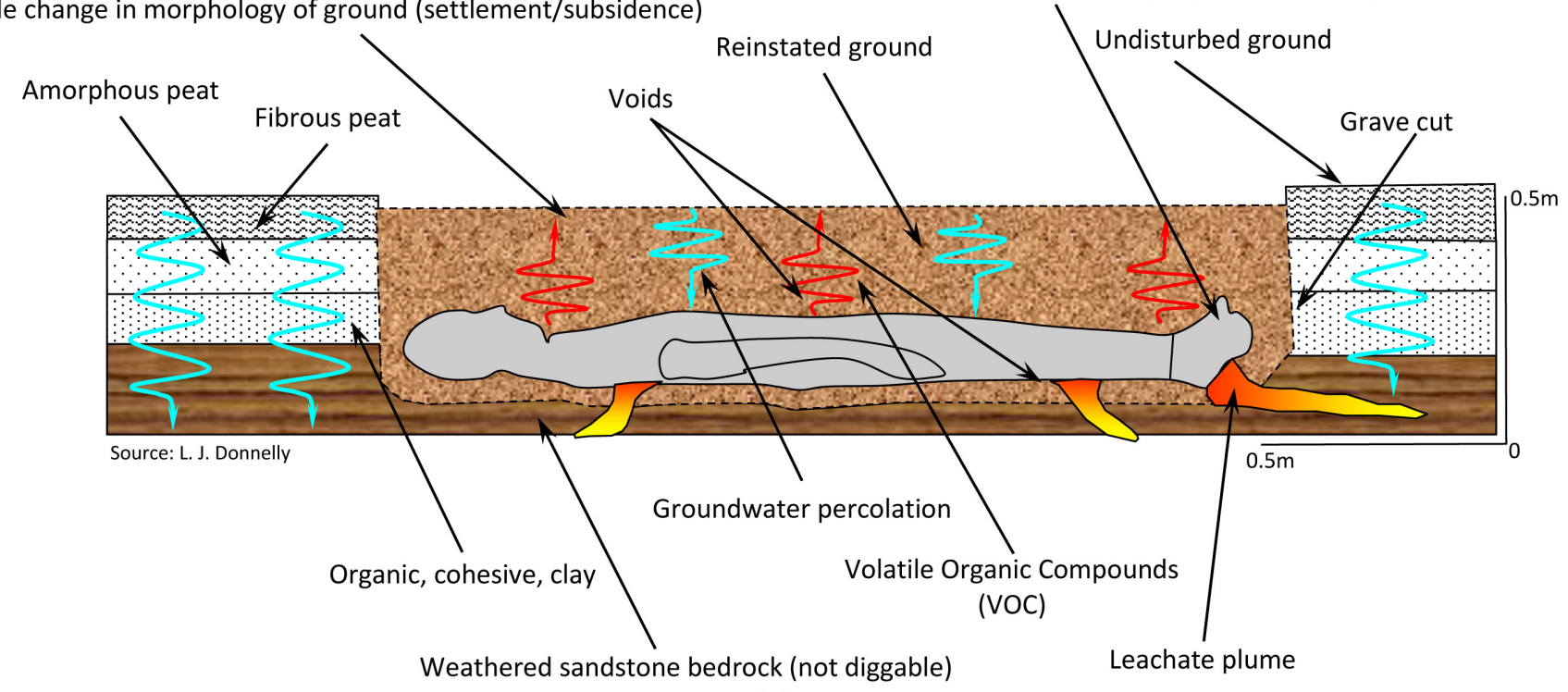

(a)

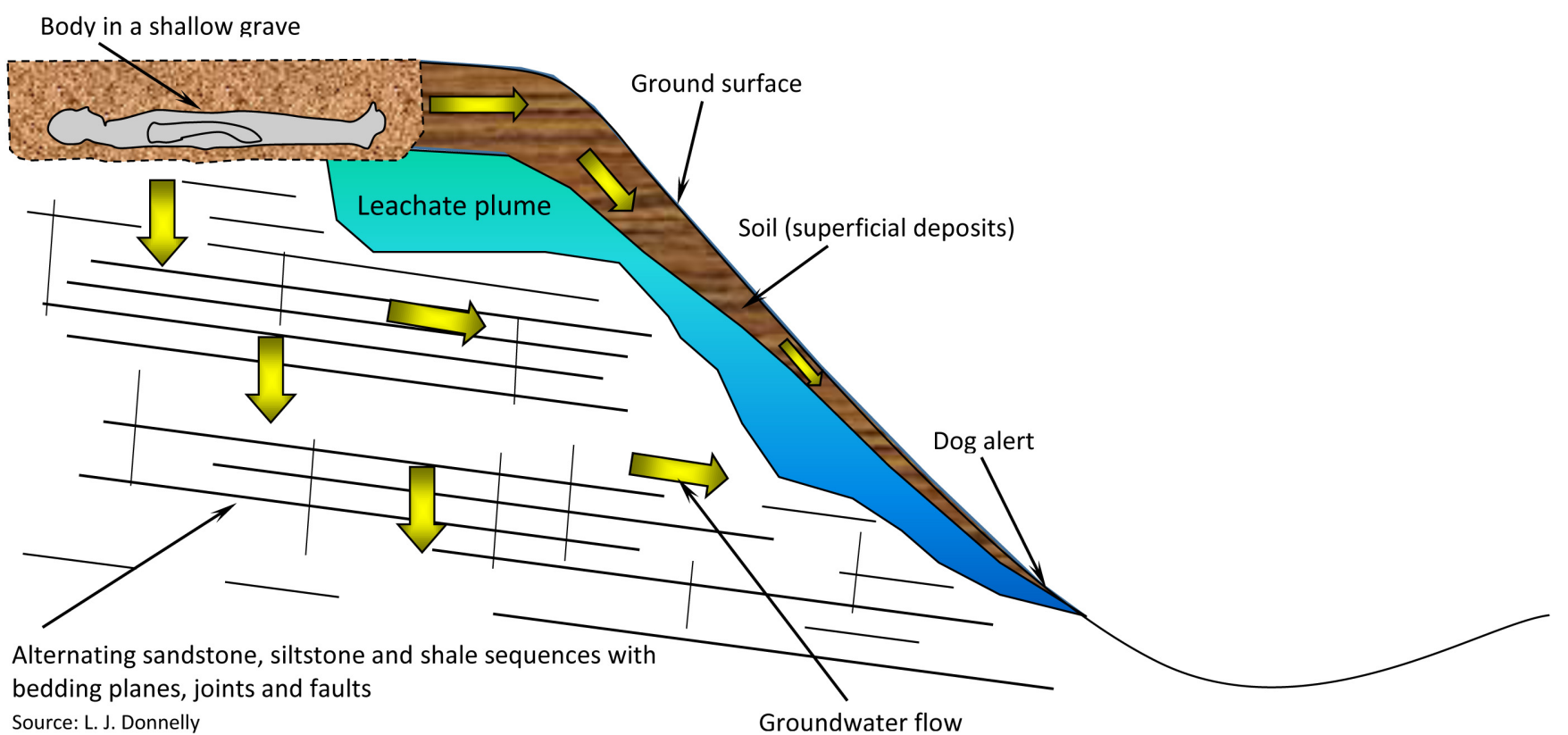

Source: L. J. Donnelly

(b)

Figure 2. Conceptual geological model and hydrogeological model for a shallow, unmarked homicide grave (Source: (C) Laurance Donnelly, Donnelly, 2008b). 
a CGM is in enabling the detectable items to be estimated, the depth of the target to be determined and the geometry, size, condition and degree of preservation or decomposition to be appraised. CGM, detectability and diggability provide the basis to identify the choice of search assets and their method of deployment. The search assets must not be chosen due to the ease of availability of a particular instrument or because a technique was successfully at another locality, were the geology and ground conditions were different (Fig. 2).

There is no single search method that is applicable in all geological settings. Generally, a suite of techniques should be deployed to increase the likelihood of the target being detected. This may include a coordinated combination of relevant victim detector dogs, geophysics and probing. The forensic geologist should contribute to a written Standard Operational Procedure (SOP). This document provides the search type, objective, location, boundary, assets, methodology and personnel. This document ensures that all members of the search team are clear on their respective roles. The SOP can also serve to assist with the formal review of the search and can help with the planning for future searches if the target is not found. The police or law enforcement officer will generally be responsible for the management and accountability of the search and the legal authority under which the search is to be implemented. Although, the responsibility for the geological components may be delegated to the geologist.

\section{Phase II: Search}

\section{Boundary}

Each search will have a different methodology depending on the search area, available assets and resources, time frames and the physical characteristics of the search area, topography, nature of the terrain and search type. If a grave is being searched for a victim detector dog should be deployed before the search areas is walked across by the search team. This may be followed by the establishment of search lanes and the cordoning of the outer search limits. Defining the outer search boundary for open area searches can be challenging. Where possible permanent physical features (e.g., streams or rock outcrops) are recommended. Some countries may have data bases that can assist to define the search outer limits, however this must be used cautiously.

\section{Lanes and Sectors}

Search lanes and search sectors may be linear, square, rectangular or irregular (Figs. 3 and 4). They should be defined by high visibility string, 'police' or 'crime scene' tape. These enable to search teams to focus on a manageable and proportionate search areas. Search lanes permit the accurate recording of any items found. Following the victim detector dog survey, geophysical surveys may be systematically deployed in each search lane or sector. This is conventionally followed by probing (auguring). Where soils are cohesive and impermeable the second deployment of the victim detector dog is recommended as the dog may detect volatile organic compounds escaping from the probe holes.

\section{Geomatics}

The search boundary, lanes and sectors and any evidential items found must be accurately recorded using a minimum of field portable global positioning system (GPS) technology. This should include information on what, when, where and how each item was found, and the names of the search team member who located and recovered the items. This information may later be required in a court of law. Therefore, the recording of the search must be consistent with the requirements of the relevant authority or criminal justice system. The method of recording a search will vary include: written notes and logs, field diagrams, digital photographs, video, compass-clinometer, tape, field portable and hand held GPS or highly sophisticated total base station GPS, 3D laser scanning and the use of a drone or UAVs. Geographic Information Systems (GIS), Digital Elevation Models (DEM), Digi-

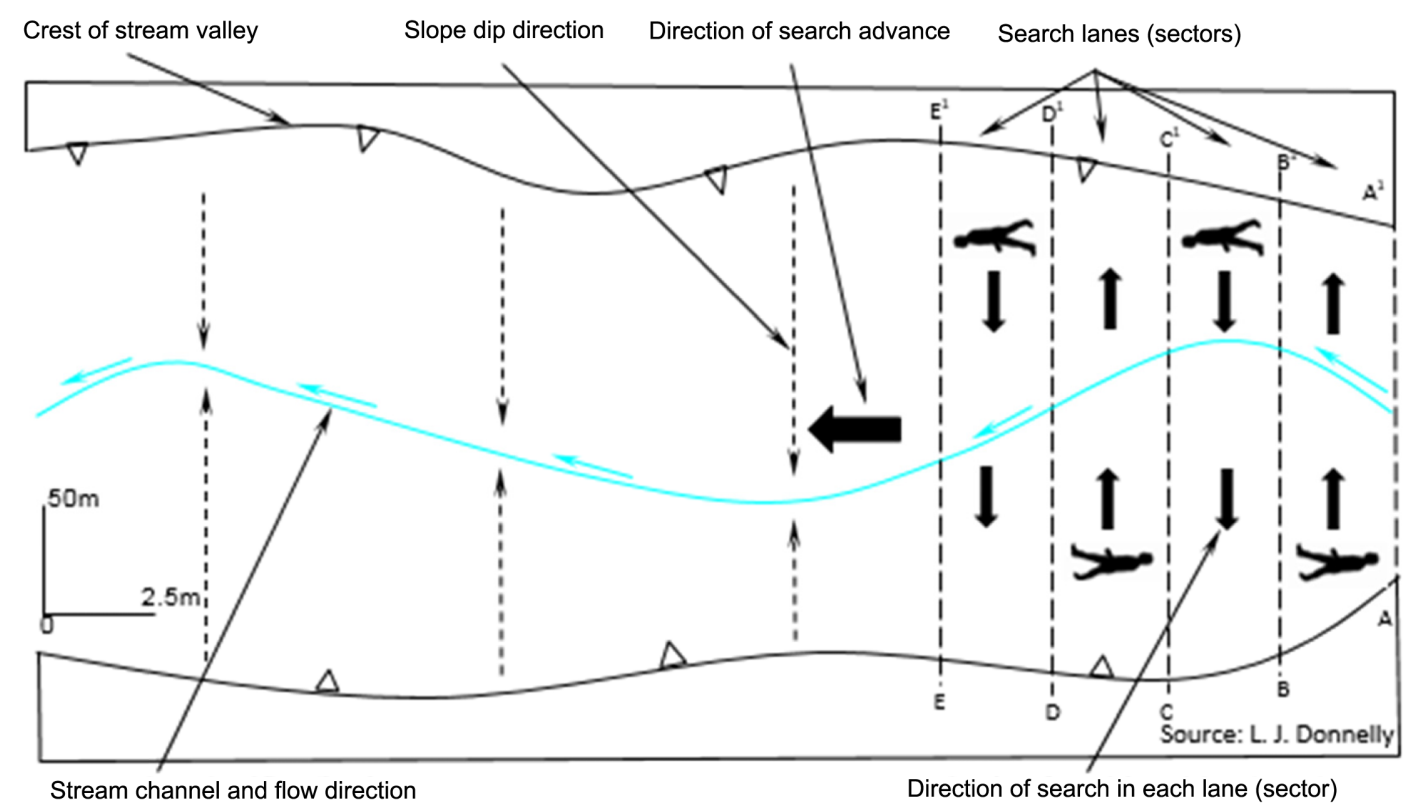

Figure 3. Examples of linear search lanes (Source: Laurance Donnelly). 


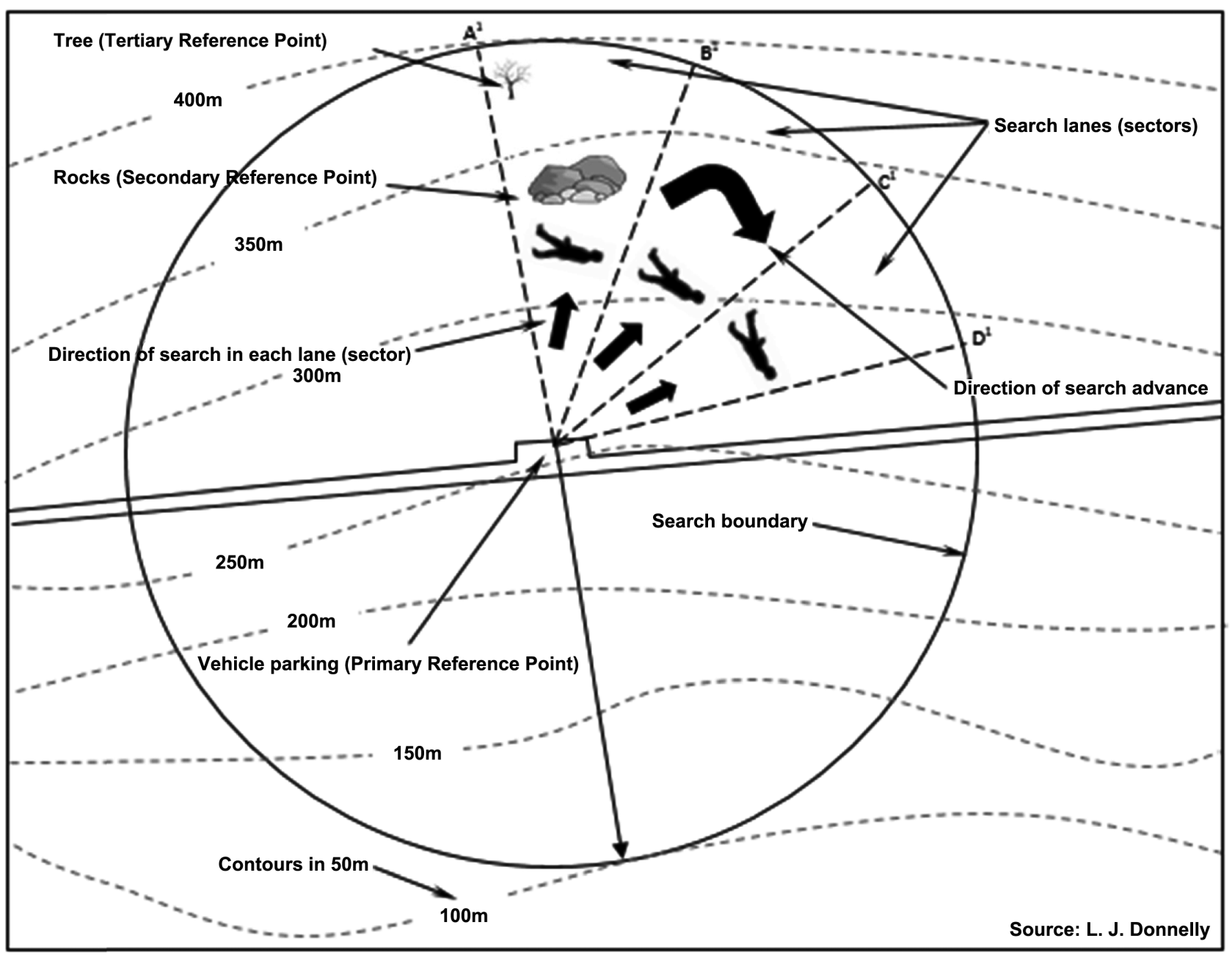

Figure 4. Examples of search sectors for a feature focused search (Source: Laurance Donnelly).

tal Terrain Models (DTM), Digital Surface Models (DSM) or Triangulated Irregular Network (TIN) are now available and can integrate and analyse geospatial data that can be used to inform the search and capture evidence. When a passenger airliner was shot down in the Ukraine, the plane broke up in the air and huge amounts of debris was distributed over many square kilometres. Aerial photography and geographic tagging of each item provided the basis for a successful search and recovery, which avoided speculative searching over large tracts of land.

\section{Controls}

The successful application of a detector dog or geophysical instrument at one location should not provide the basis for the untested deployment of these search assets at another geographic locality where the geology may be different. Before the start of a search, controls should be established to verify the suitability of the search assets. If the geology is variable across a search area it may be necessary for more than one control site to be established. A control site provides the opportunity to validate the conceptual geological model for the search and to test whether the search assets are fit-for purpose. Forensic geophysical surveys should be conducted following the establishment of a control site. This requires the burial of items similar in composition and size the target being sought. This must be buried in an area of similar geology to the search area. The control site allows the depth detection and resolution limits of the geophysics to be determined, provides the opportunity for the instruments to be calibrated and allows training for police officers that have been assigned to the search but are not familiar with the operational use of the instruments. Detector dog controls may include the burial of mummified pig remains. However, care should be taken to avoid cross-contamination and the location of the controls should be beyond the search area but in similar geology. The added benefit of a control site is in allowing new search team members to become familiar with the operation of the search instruments, instead of 'training' during the actual search. The search assets should be tested before and at the end of each search phase or day. Soil probes (augers) may also be tested on the controls so the search teams can recognised the characteristic bounce-back when a buried target is intersected, the dropping of the probe if a void is present above a decomposed body or the recovery of part of the target (e.g., bone or material from clothing) in the window of the auger.

\section{Leachate Plumes and VOCs}

During the decomposition of human remains volatile organic compounds (VOC's) and odour may be generated (Vass et al., 2004, 2008; Vass, 2012). Leachate have also been observed flowing from human 

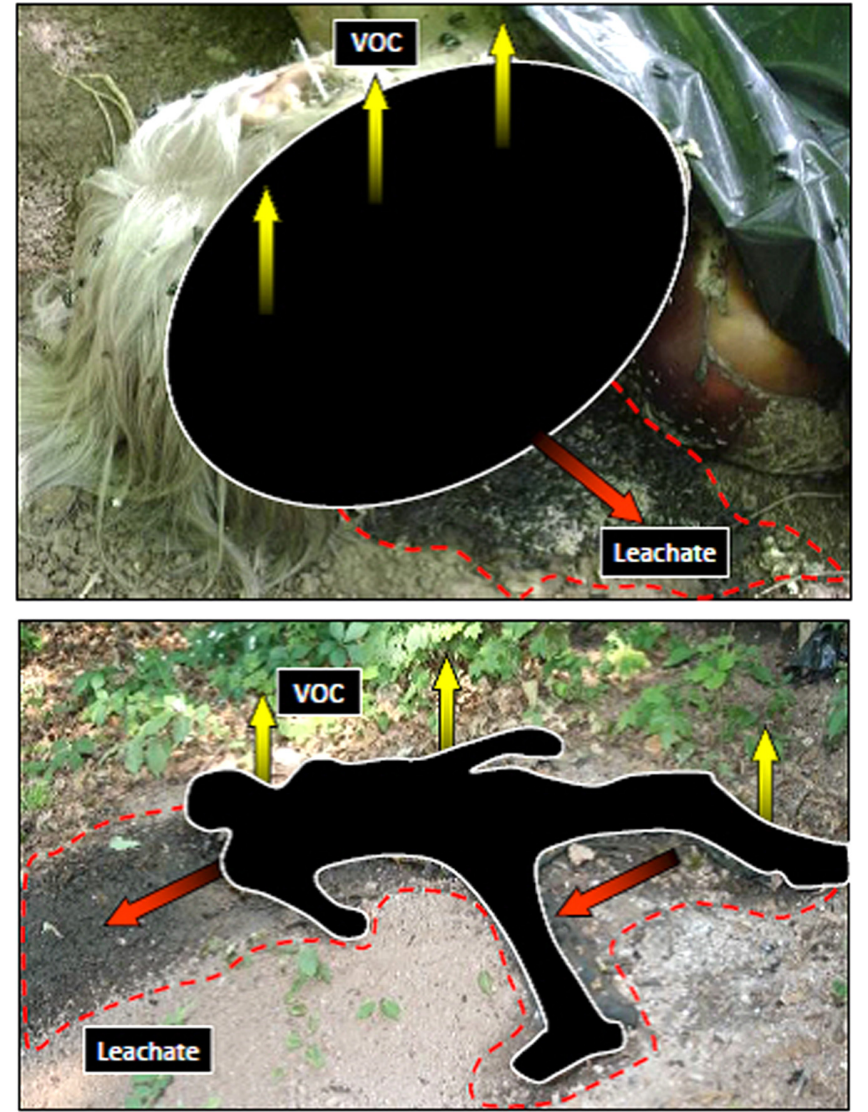

Figure 5. Unidirectional leachate plumes and volatile organic compounds (VOCs) from human remains placed on gentle sloping ground (Photos: Laurance Donnelly, photographs from 'The Body Farm' University of Tennessee, Department of Forensic Anthropology, Knoxville, Tennessee, USA).

remains, influenced by the geology and direction and amount of dip of the ground surface as noted in Figure 5.

It is suspected by the authors that leachate plumes generated from a clandestine grave (source) may possibly migrate and flow in permeable soils and rocks (pathways) to emerge at a spring or seeps where they may be detected by the victim recovery $\operatorname{dog}$ (VRD).

During the search for a homicide grave VRD responses were noted at interfaces between soil layers. These false-positive indications were thought to be possibly influenced by the detector dog responding to VOC's associated with human decomposition. Subsequently, these scents were considered as emerging at seeps and springs, driven by a hydraulic gradient. An understanding of the geology and hydrogeology of a search area may therefore possibly enable the source (grave) to be located if the pathways and groundwater flows are better understood.

In the case resented in Figure 6, responses were observed by three separate VRD's, over four years in the vicinity of three past graves. The subsequent analysis of soils enabled the delineation of a possible leachate plume containing VOCs that were possibly associated with human decomposition (Fig. 6).

The migration and detectability of the VOC's and leachate are dependent on several factors, such as the geology, topography, geomorphology and hydrogeology of the burial site, and circumstances of the burial.

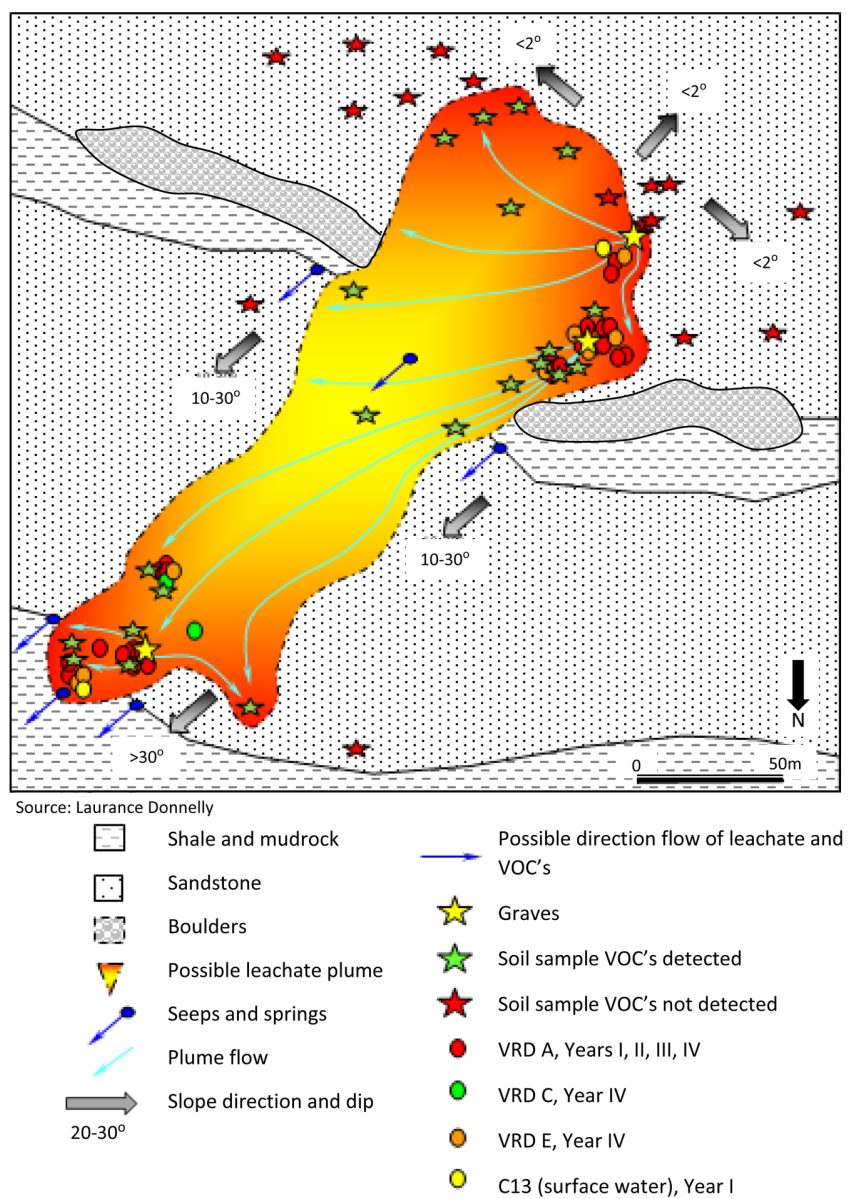

Figure 6. Conceptual leachate plume generated several years after victims were discovered. Based on an evaluation of the geology, geomorphology and hydrogeology, detector dog indications and the results of soil analysis for volatile organic compound (Source: Laurance Donnelly).

Following the discovery of a 15 -year-old grave, soils samples were taken from beneath the body, upslope, down slope, along strike from the grave. A control sample was also taken in an area of similar geology but well beyond the influence from the grave. The soil was taken with a $30 \mathrm{~mm}$ diameter and $1.2 \mathrm{~m}$ long auger and transferred in $40 \mathrm{ml}$ glass vials that had a screw cap and polypropylene septa. The leachate, organics and mineralogy were analysed and results compared to the equivalent control sample. The geology comprised strong, welljointed, coarse grained, feldspathic sandstones of Namurian age, overlain by Periglacial deposits and organic peat soils that was envisaged to facilitate plume generation. Elevated levels of putrescence was measured at nearly $150 \mathrm{ppb}$ at the grave, downslope and for several meters upslope at localities where detector dogs had showed an interest before the grave was discovered. The mineralogical analysis, using integrated automated mineralogy and petrology (QEMSCAN), detected the presence of calcite (at an abundance of less than 1\%) in the soil profile beneath the grave. No calcite was detected using automated analysis in any of the other samples analysed. The texture of the calcite as imaged using scanning electron microscopy indicates that it is likely to be diagenetic in origin, precipitated within the soil profile rather than being detrital in origin. Calcite was not detected by XRD in any of the samples analysed, although this could be due to its 
low level of abundance. Additionally, the organic analysis detected the presence of elevated stanols at the grave site and downslope. The preliminary results are interesting and further research is required to test whether this approach can be reliably applied operationally to open area searches for burials (Donnelly et al., 2016).

\section{Victim Recovery Dogs}

Victim Recovery Dogs (VRD's) (also known as victim detector dogs, cadaver dogs, body dogs and sniffer dogs) can be trained to detect buried
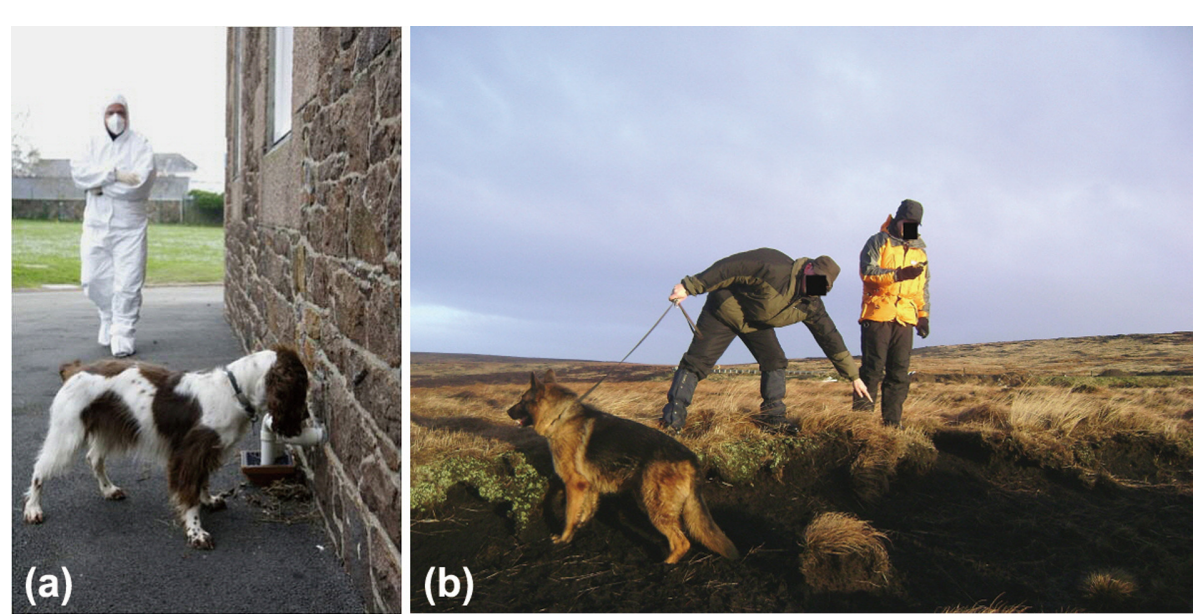

Figure 7. Deployment of victim detector dogs as part of a forensic geology search strategy (Source: Donnelly \& Harrison, 2010 (a) and Laurance Donnelly (b)). human remains, currency, explosives, firearms or drugs. The dogs obey the 'Scent-Pathway-Receptor' (CPR) model by detecting VOC's (known also as scent or odour). The training, handling and deployment of detector dogs is a highly specialised skill. Interestingly, the success of a detector dog seems to be only partially understood. It is suspected that ability of a search dogs may be influenced geological and environmental factors, including for example groundwater flows and leachate plumes, soil permeability, wind direction and speed and barometric pressure fluctuations (Donnelly et al., 2013) (Fig. 7).

The ground investigation of positive detector dog responses may, or may not, result in the recovery of human remains. Where human remains are not evident in the immediate vicinity there is a tendency is to classify the VRD response as incorrect and a search may be halted as a consequence. However, this may occur when the VRD responses are wrongly interpreted by investigators. In cases where the search area has been extended beyond the VRD response site victim's remains have subsequently been recovered in a near-by grave. This may possibly be explained by an understanding of the geology and groundwater flows as noted above. The search for a grave presented in Figure 8 shows the consistent distribution of false-positive VRD indications provided by four detector dogs deployed of a four years period. The location of the false-positive responses were

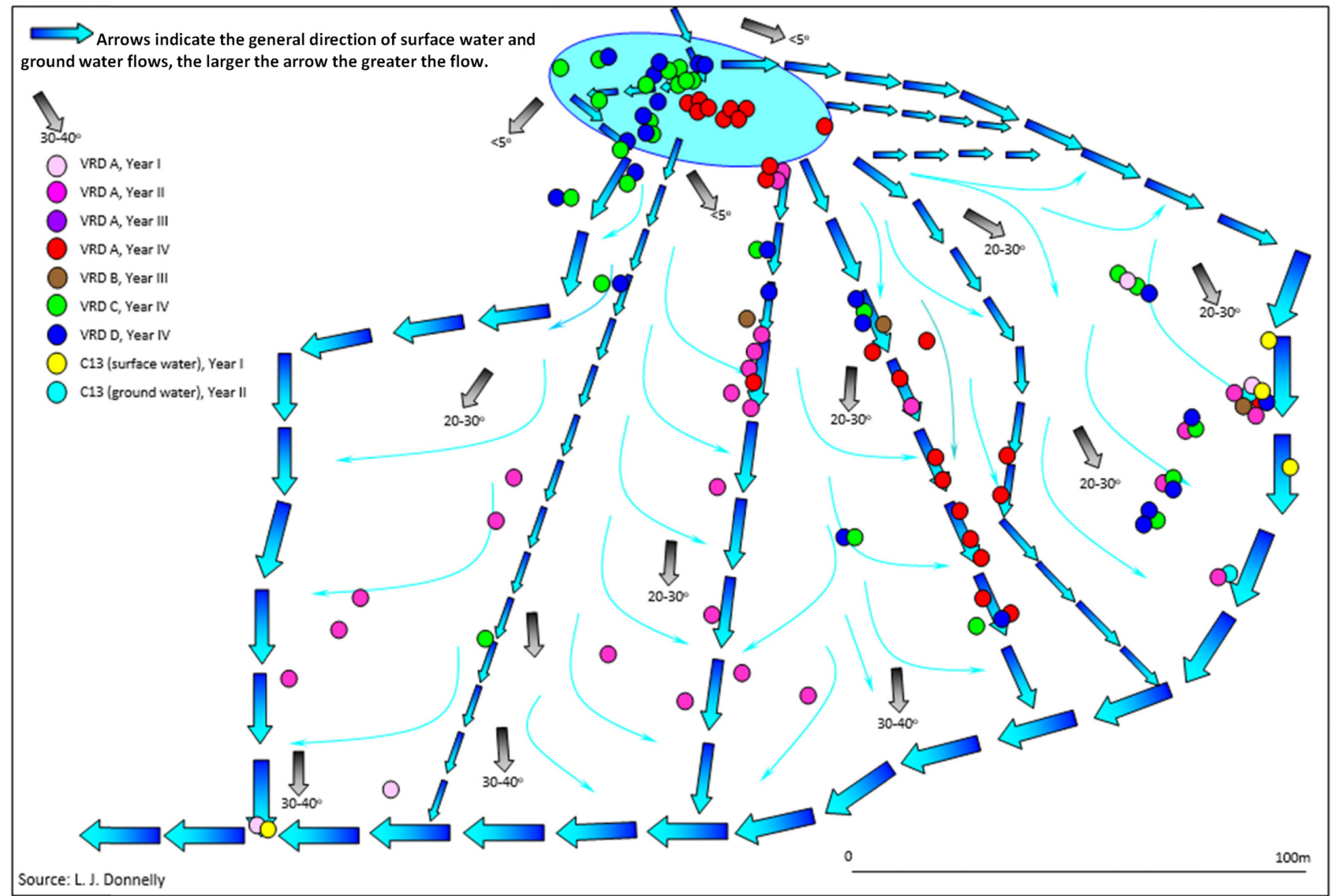

Figure 8. Distribution of false-positive VRD indications combined with surface water and groundwater flow paths (Source: Laurance Donnelly). 


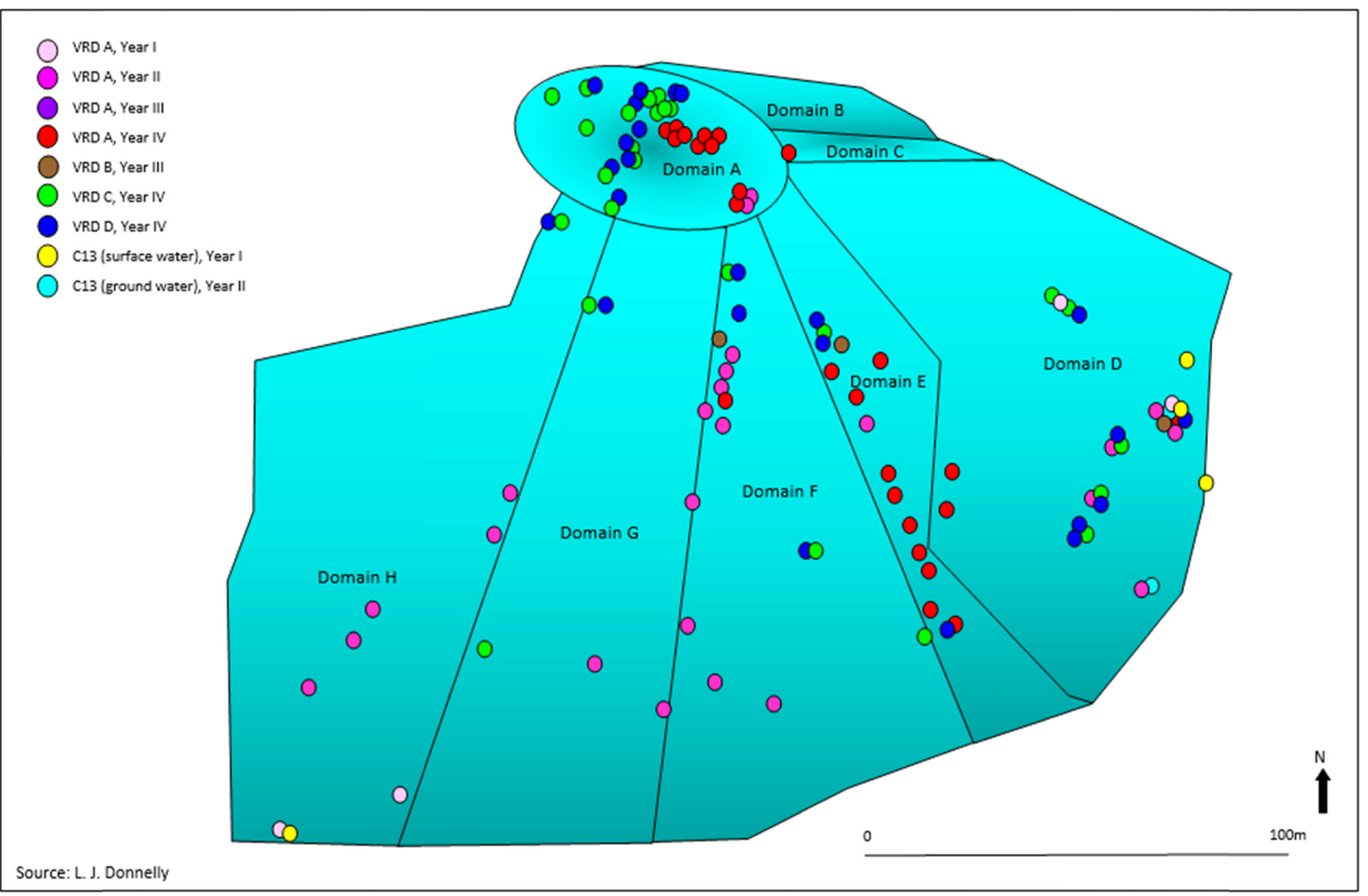

Figure 9. Conceptual hydrogeological domains (cells) (Source: Laurance Donnelly).

generally consistent with the surface and groundwater flows and the location of seeps and springs across the search area. A detailed hydrogeological evaluation subsequently enables the open search area to be dub-divided into a series of hydrogeological domains (cells), which facilitated the management of the ground search (Fig. 9).

\section{Geochemistry}

Stable Isotope Profiling (SIP) may potentially have applications for searches. SIP can assist to provenance food, human remains (hair, teeth, nails, bone), drugs, and explosives. This is based on the premise that human remains, including fats, proteins and carbohydrates, break down following death into their constituent parts. Eventually, the breakdown of dissolved organic carbon (DOC) may produce dissolved inorganic carbon (DIC). If the DOC and DIC leach into soils and groundwater plumes, and can be detected and analysed, this potentially may infer the presence of human remains altering the carbon signature of the soil (Meier-Augenstein, 2011).

\section{Geophysics}

Geophysics may be deployed as part of a search strategy to locate burials. This can be deployed over a point, line (traverse) or area, from the air or ground based, over land or in water. Unfortunately, there is no single method that can locate all types of burials in all geological settings (Fig. 10). Therefore, the choice of geophysical instruments can only be determined when the case intelligence has been provided by

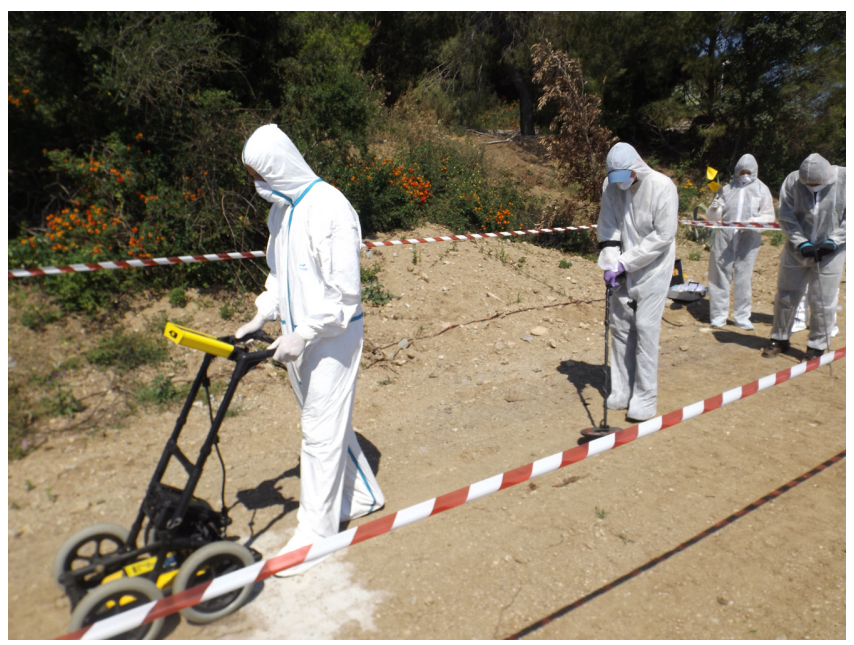

Figure 10. Geophysical search for a buried target. IUGS-IFG University of Messina, Sicily (Photo: Laurance Donnelly and University of Messina).

the police and geology of the search area has been evaluated by a geologist. This may be facilitated by the production of a desktop study (e.g., solid and drift geology; soil, land use, past land use changes, satellite/aerial imagery) and creation of a conceptual geological model, from which an assessment of the ground diggability and detectability of the target may be made. Geophysical surveys are not generally suitable to locate human remains, but often may detect the presence of any associated items (such as clothing), a grave cut or changes in the 

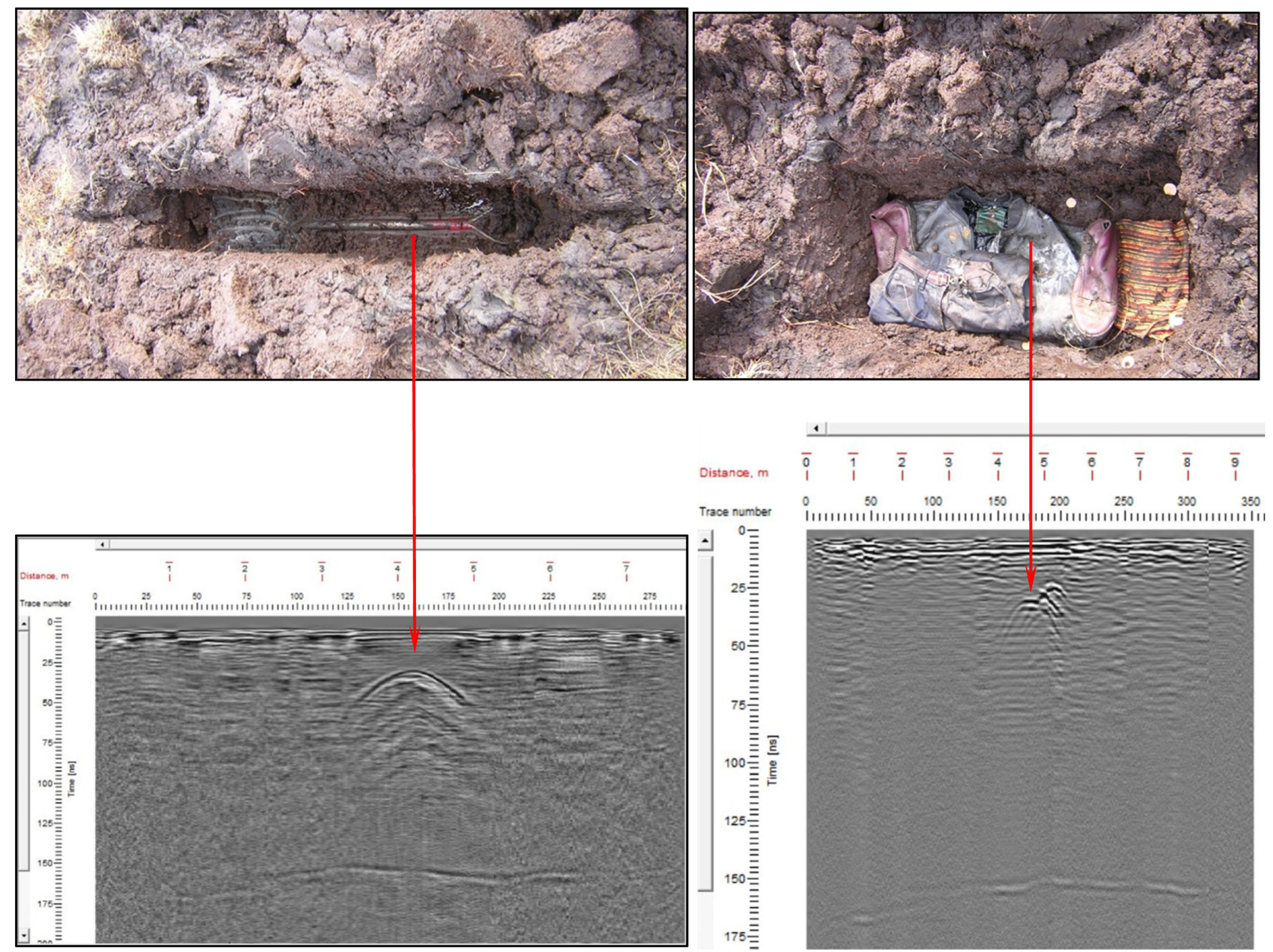

Figure 11. Ground penetrating radar surveys above a buried spade (Photo: Laurance Donnelly. Radar gram courtesy of Mike Langton and Alistair Ruffell) (Donnelly, 2017).

geotechnical and physical properties of the backfilled soils. Common methods used in ground searches include ground penetrating radar (GPR), resistivity, magnetometer and electromagnetic surveys. However seismic refraction and microgravity may also be required in some cases (Fig. 11). It should be noted that geophysics alone will not give a guarantee for the presence of absence of a buried target. Two or three complementary methods are recommended to be deployed consecutively and in a phased manner as part of a planned search strategy. Further details on the application of geophysics to law enforcement ground searches and cases be found in Fenning and Donnelly (2004), Pringle et al. (2012), and Ruffell (2005).

\section{Auguring}

Geophysical and detector dog anomalies may be investigated by the use of a soil steel probe or an auger that contains a 'window' for the examination of the soil stratigraphy. Augers vary in length although tend to be approximately $1.2 \mathrm{~m}$ long. Target detection is verified by the presence of a small piece of the target (e.g., bone of clothing) in the window of the auger, the refusal of the auger to penetrate to deeper layers or the bounce back of the auger when the target is interested.
Auguring is most effective when used by a line of search trained geologists or police officers at no less than approximately $0.2 \mathrm{~m}$ spacing, or as otherwise may be considered appropriate. Auguring and the use

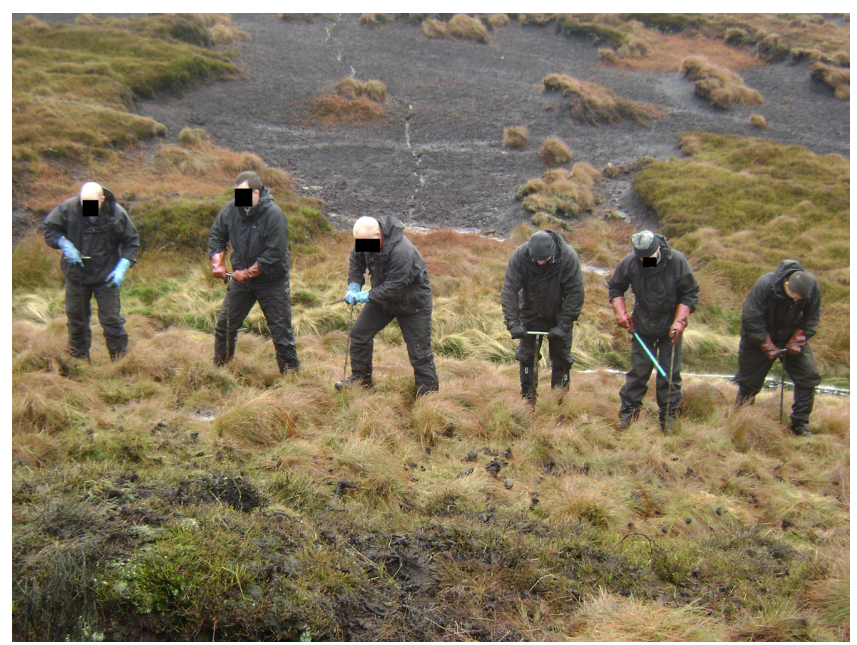

Figure 12. Line of search trained police officers auguring to locate a burial in Europe (Photo: Laurance Donnelly). 
of probes can cause the emission of gases or volatile organic compounds from impermeable soils, which can enhance the possibility of detection by a trained detector (Fig. 12).

\section{Phase III: Post Search}

\section{Recovery}

Once a target has been located the formal identification and forensic recovery usually rests beyond the experiences and training of most forensic geologists. A forensic archaeologist may be called upon to assist with identification and recovery (Hunter et al., 2013). Although, the identification and collection of any soil will require to be managed between the geologist and archaeologist or crime scene manager. The soil may be subsequently analysed to determine a geographic provenance or if there was an association with an offender or other questioned item. All items recovered must be consistent with approved guidance, as these may need to be subsequently exhibited and admissible in a court of law. The location of each find requires accurate recording using GPS and possibly the services of a professional crime scene mapping specialist. The recovery of human remains, hazardous and potentially explosive items will require specialist forensic or military support to ensure the optimal level of evidential material whilst ensuring forensic provenance, safety and integrity. Evidential finds and human remains must be properly labelled, exhibited and recorded.

\section{Excavation}

The type and scale of excavation can vary considerable from the use of an air brush to mechanised diggers. Generally, auguring, the digging of narrow exploratory trenches and the horizontal stripping of soils facilitates the recovery of the buried target. Due care is required to ensure the stability of any excavations and displaced soils and gas monitoring might be might be required in some geological settings to detect the presence of dangerous levels of noxious, explosive or asphyxiant gasses.

\section{Levels of Assurance}

The completion of a forensic geology led search requires accurate recording and reporting. This should comprise a statement on the levels of assurance and degree of geological confidence to verify the presence or absence of the target being sought within the area searched, and within the capabilities of the instruments and search assets deployed. It should be noted that the provision of new intelligence at a later date or advances in search assets, techniques, resolution and detection limits may result in the case and search being reported and then reopened. Under these circumstances the archive data and associated reports will be of value. It is therefore important for the geology, search strategy, methodology, area searched and the position of items found to be accurately reported.

\section{Debrief}

A search debrief gives the opportunity for the forensic geologist, law enforcement officer(s) or search and rescue personnel, and search team to consider the search and reflect on the search activity. This may also be required to be formally recorded depending on the local criminal legal framework and the context of the search.

\section{Exit Strategy}

A well planned, managed and implemented search may not have the expected outcome. Searches therefore benefit from a pre-determined and defined exit strategy.

\section{Acknowledgements}

The authors would like to acknowledge the support and contributions from Prof. Arpad Vass and Mr. Martin Grime.

\section{References}

Association of Chief Police officers (ACPO), 2012, Manual of Guidance for Police Search Advisers (PolSA): College of Policing, London, v. $1,17 \mathrm{p}$.

Donnelly, L.J., 2017, International Union of Geological Sciences (IUGS), Initiative on Forensic Geology (IFG). Chair's Annual Report for 2016.

Donnelly, L.J., 2013a, The applications of forensic geology and geophysics for police and law enforcement ground searches: $2^{\text {nd }}$ International Conference on Engineering Geophysics, Keynote Presentation, United Arab Emirates University, Al Ain, November 24-27, pp. 82-86.

Donnelly, L.J., 2013b, The design and implementation of a high assurance forensic geology and police search to verify total gold recovery following the discovery of the Staffordshire (Anglo Saxon) Gold Hoard. in Pirrie, D., Ruffell, A.R., and Dawson, L. (eds.), Environmental and Criminal Geoforensics: Geological Society of London, Special Publication, v. 384, pp. 195-208.

Donnelly, L. J., 2008a, Communication in geology: a personal perspective and lessons from volcanic, mining, exploration, geotechnical, police and geoforensic investigations. in Livermann, D.G.E., Pereira, C.P., and Marker, B. (eds.), Communicating environmental geoscience: Geological Society of London, Special Publication, v. 305, pp. 107-121.

Donnelly, L.J. (ed.), 2008b, Geoscientific equipment and techniques at crime scenes. $2^{\text {nd }}$ FGG Meeting of the Geological Society of London, Forensic Geoscience Group, Programme \& Abstracts, Burlington House, London, December 17, pp. 6-7.

Donnelly, L.J., Cassella, J., Pirrie, D., Dawson, L., Harrault, L., Blom, G., Davidson, A., Arnold, P., Harrison, M., and Ruffell, A., 2016, Analysis of leachate, VOCs, fatty acids and mineralogy following the discovery of a homicide grave: potential implications for police led open area ground searches for burials: $35^{\text {th }}$ International Geological Congress, Cape Town, August 29, T6.1 - Forensic Soil Science and Geology.

Donnelly, L.J., Grime, M., and Harrison, M., 2013, Interpretation of Victim Recovery Dog (VRD) responses during ground searches for homicide graves and the potential influences of geology, hydrogeology, peat stratigraphy and barometric pressure fluctuations: IUGS-IFG RFCFS, Moscow, October 22, Booklet of Abstracts, p. 16-17, (in English) p. 18-19. (in Russian)

Donnelly, L.J., and Harrison, M., 2015, A collaborative methodology for ground searches by a forensic geologist and law enforcement (police) officer: detecting evidence related to homicide, terrorism and organized crime: Proceedings of the $3^{\text {rd }}$ International Conference on Engineering Geophysics, Session on Forensic Geosciences, Al Ain, UAE, FG02, pp. 260-268.

Donnelly, L.J., and Harrison, M., 2013, Geomorphological and geoforensic interpretation of maps, aerial imagery, conditions of diggability and 
the colour coded RAG prioritisation system in searches for criminal burials. in Pirrie, D., Ruffell, A.R., and Dawson, L. (eds.), Environmental and criminal geoforensics: Geological Society of London, Special Publication, v. 384, pp. 173-194.

Donnelly, L.J., and Harrison, M., 2010, Development of geoforensic strategy \& methodology to search the ground for an unmarked burial or concealed object: Emergency Global Barclay Media Limited, July 2010, pp. 30-35.

Fenning, P.J., and Donnelly, L.J., 2004, Geophysical techniques for forensic investigations. in Pye, K., and Croft, D. (eds.), Forensic geoscience Principles, techniques and applications: Geological Society of London, Special Publications, v. 232, pp. 11-20.

Harrison, M., and Donnelly, L.J., 2009, Locating concealed homicide victims: developing the role of geoforensics. in Ritz, K., Dawson, L., and Miller, D. (eds.), Criminal and environmental soil forensics: Soil Forensics, Springer, pp. 197-219.

Harrison, M., and Donnelly, L.J., 2008, Buried homicide victims: Applied geoforensics in search to locate strategies: The Journal of Homicide and Major Incident Investigations, Produced on behalf of the Association of Chief Police Officers (ACPO) Homicide Working Group, by the National Policing Improvement Agency (NPIA).

Harrison, M., and Donnelly, L.J., 2007, The coordinated approach of multi-disciplinary teams to locate concealed victims of homicide, developing the role of forensic landscape investigation: Soil Forensic International, October 30-November 1, The Macaulay Institute, Herriot Watt University, Edinburgh.

Harrison, M., Hedges, C., and Sims, C. (eds.), 2006, Practical advice on search management and procedures. National Policing Improvement Agency (NPIA), UK.

Hunter, J., Simpson, B., and Colls, C.S., 2013, Forensic approaches to buried remains: Wiley- Blackwell, Chichester, $278 \mathrm{p}$.

Meier-Augenstein, W., 2011, Stable isotope forensics: An introduction to the forensic application of stable isotope analysis: Wiley, Somerset, $271 \mathrm{p}$.

Pirrie, D., Power, M., Rollinson, G.K., Wiltshire, P., Newberry, J., and Campbell, H., 2009, Automated SEM-EDS (QEMSCAN $®)$ mineral analysis in forensic soil investigations: Testing instrumental reproducibility. in Ritz, K., Dawson, L., Miller, D. (eds.), Criminal and environmental soil forensics: Springer, pp. 411-430.

Pringle, J.K., Ruffell, A., Jervis, J.R. Donnelly, L.J., McKinley, J., Hansen, J., Morgan, R., Pirrie, D., and Harrison, M., 2012, The use of geoscience methods for terrestrial forensic searches: Earth Science Reviews, v. 114 , no. $1-2$, pp. 108-123.

Ruffell, A., 2005, Searching for the IRA "disappeared": Ground penetrating radar investigation of a churchyard burial site: Journal of Forensic Sciences, v. 50, no. 6, pp. 1430-1435.

Ruffell, A., 2006, Under-water scene investigation using ground penetrating radar (GPR) in the search for a Sunken Jet ski, northern Ireland: Sci- ence \& Justice, v. 46, no. 4, pp. 150-159

Vass, A.A., 2012, Odor mortis: Forensic Science International, v. 222, no. $1-3$, pp. 234-241.

Vass, A.A., Smith, R.R., Thompson, C.V., Burnett, M.N., Dulgerian, N., and Eckenrode, B.A., 2008, Odor analysis of decomposing human remains: Journal of Forensic Science, v. 53, no. 2, pp. 384-392.

Vass, A.A., Smith, R.R., Thompson, C.V., Burnett, M.N., Wolf, D.A., Synstelien, J.A., Eckenrode, B.A., and Dulgerian, N., 2004, Decomposing odor analysis database: Journal of Forensic Science, v. 49, no. 4, pp. 760-769.

Wiltshire, P.E.J., 2009, Forensic ecology, botany and palynology: some aspects of their role in criminal investigation. in Ritz, K., Dawson, L., and Miller, D. (eds.), Criminal and environmental soil forensics: Springer, pp. 129-14.

Wiltshire, P.E.J., 2015, Protocols for forensic palynology. Palynology, v. 40, no. 1, pp. 4-24.

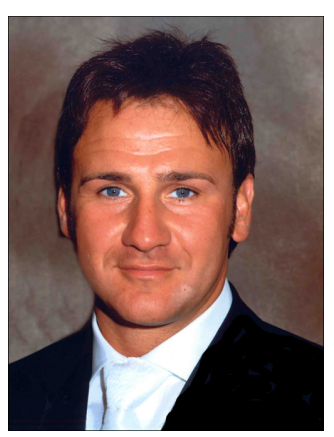

Laurance Donnelly is a professional, chartered, geologist with a first class honours degree (BSc) in Applied Geology and Ph.D. in Geohazards. He has 27 years of international experiences in; mineral exploration, mining geology, engineering geology, geohazards and forensic geology. He has pioneered new ground search strategies for graves and other burials related to homicide, serious organised crime and terrorism. He has also advised the police on cases involving geological trace evidence. He is registered as an Expert Adviser with the UK National Crime Agency. He is the founder of the IUGS Initiative on Forensic Geology and Geological Society of London, Forensic Geoscience Group.

Mark Harrison, M.B.E. has 30 years of experience as a senior law enforcement officer. He has developed capabilities and expertise for land and marine searching, assisting over 300 investigations throughout the world for missing persons, victims of homicide and concealed weapons and drugs from organised crime and terrorist groups. He has received national and international awards for his contributions to serious crime and terrorism. $\mathrm{He}$ is active in academia driving research in the fields of geoforensics, forensic intelligence and criminal investigations. 